\title{
DEVELOPING A PREDICTION MODEL FOR TENSILE ELASTIC MODULUS OF STEEL FIBER - CEMENT STABILIZED LATERITE USED AS PAVEMENT MATERIAL
}

\author{
Emmanuel O. Ekwulo1, Enwuso A. Igwe ${ }^{2}$ \\ ${ }^{1}$ Department of Civil Engineering, Rivers State University of Science and Technology, \\ Nkpolu Oroworukwo, P.M.B, 5080, Port Harcourt, Rivers State, Nigeria \\ ${ }^{2}$ Department of Civil Engineering, Rivers State University of Science and Technology, \\ Nkpolu Oroworukwo, P.M.B, 5080, Port Harcourt, Rivers State, Nigeria
}

\begin{abstract}
This paper attempts to develop a prediction model that can be safely used in line with prescribed laboratory experiments (indirect tensile test) such that tensile elastic modulus can be predicted for cement stabilized lateritic soil reinforced with steel fiber using measured properties of the material. The results of the tensile elastic modulus obtained from the Derived Prediction Model almost nearly replicates that obtained from calculations from laboratory experimentation. Results obtained revealed that both the predicted values and calculated values have a linear correlation with an $R^{2}$ of $96.4 \%$. On this basis the Derived Prediction Model can be said to be valid within the limits of the study.
\end{abstract}

Key words: Steel Fiber Reinforcement (SFR), Tensile Elastic Modulus, Cement Stabilized Lateritic soil

\section{INTRODUCTION}

There are two main types of approach in the characterization of materials used in structural design of flexible pavement: the conventional or empirical method and the rationale or mechanistic design approach. While the former is still widely used in most developing nations of the world; the latter has gained more grounds in the developed nations because of its greater reliability in terms of the inherent properties that are of interest to the highway engineer. The advantage of the latter over the former is that it requires the determination of elastic and resilient properties of the materials to be used for design which controls the overall behaviour and therefore performance of the pavement during its useful life (Oguara, 2005).

The mechanistic design of roads with cement stabilized and steel fiber-reinforced lateritic soil requires an adequate knowledge of the elastic properties of the material. The rationale or mechanistic design methods involve an analytical approach that depends on the laws of mechanics to predict critical stresses and strains by using the elastic parameters (Oguara, 1985). Furthermore, in mechanistic design methods of flexible pavement, the materials in each layer of the pavement are characterized by their modulus of elasticity, E and poisson's ratio, $\mu$ (Oguara and Emesiobi, 2001). During characterization the developed tensile and compressive strains due to repetition of wheel load application are then used for fatigue analysis and permanent deformation (rutting) assessment (Emesiobi, 2004b).
The introduction of steel fibers as reinforcement to lateritic soils used as pavement material is a relatively new technology for producing a relatively inexpensive material of high strength (Ekwulo and Igwe, 2009). Hancork and Cuthberton (1970) studied the effect of fiber and interfacial bond in glass fiber-epoxy resin composites and concluded that the addition of steel fibers to pavement materials retard the propagation of cracks and sometimes dislocation of the matrix. In similar studies Shahid and Thom (1998) investigated the effect of steel fibers on cement bound bases. Their result showed that the addition of steel fibers to cement bound material base produced significant improvement in the tensile properties of the material which further provides extra safety against longitudinal cracking.

The modulus of elasticity whether in tension, compression or shear is another property of concern in mechanistic design of pavement. Nakagawa et al (1988) and Naaman (1999) conducted tests for tensile modulus of elasticity for fiber reinforced cement based composites. Their separate results showed that modulus of elasticity increased with increase in the fiber content.

Poisson's ratio is another important parameter used in elastic analysis and design of pavement systems. Studies have revealed that Poisson's ratio can vary between 0-5 (Pavement Interactive Core series, 2008). Furthermore, stiffer materials tend to have lower Poisson's ratio than softer materials since the strain normal to applied stress will be small due to rigidity; thus the ratio of strain normal to the applied stress to that parallel to the applied stress will be small which describes Poisson's ratio. In simple terms Poisson's ratio is defined as 


$$
\mu=\varepsilon_{x} / \varepsilon_{y}
$$

Where, $\varepsilon_{\mathrm{x}}=$ strain normal to the applied stress

$\varepsilon_{\mathrm{y}}=$ strain parallel to the applied stress

$\mu=$ Poisson's ratio

The determination of elastic modulus whether in tension, compression or shear usually involves the application of equations based on the simple law of motion from physics in the elastic region. However, the parameters of the equation are obtained from laboratory experiments. The indirect tensile test methods have been used by various researchers in the determination of elastic properties in the analysis and design of pavement systems in Nigeria - Adedimila and Ashade (1993); Oguara et al (2001); Emesiobi and Aitsebaomo (2002) and Emesiobi (2004a).

Adedimila and Emina (1985) had done a previous study using the indirect tensile test methods to conduct the stripping potential of Nigeria's Asphalt mixtures. Their study revealed that it can be a complement for Marshall Stability test.

Also of interest to the highway engineer is the need to improve the performance of the individual materials that make-up a road pavement. A typical flexible pavement will consist of a wearing course comprising of asphalt concrete, base course, sub-base course for weaker soils and the subgrade. It is pertinent to say that in most cases these different layers beneath the wearing course do not have adequate material property quality and therefore will require remediation in many cases. One of such measures of remediation is stabilization of the base and sub-base courses used as road pavement materials. It is common knowledge that lateritic soils are the most widely used road pavement materials in road construction as bases and sub-bases because of its availability. However, in most cases these materials do not meet specification requirements and therefore need to be improved either by stabilization or other procedures.

According to Oguara (1985) stabilization is the modification of soils or aggregates by incorporating materials that will increase load bearing capacity, firmness and resistance to weathering or displacement under traffic loads. These materials used for the stabilization are mostly referred to as additives, admixtures, stabilizing agents or stabilizers. Examples include cement, bitumen and lime. Others include salts such as calcium chloride, sodium chloride, magnesium chloride and organic compounds. However, for the purpose of the present study steel fibers were used to reinforce cement stabilized lateritic pavement material.

Ekwulo and Igwe (2009) studied the effects of steel fiber reinforcement on cement stabilized lateritic soil used as pavement material with respect to cracking. Their results revealed that the addition of steel fiber as reinforcements to the cement stabilized lateritic soil increased tensile strength by $50 \%$ and also increased elastic tensile modulus by $21 \%$. Furthermore, the failure mode for the steel fiber reinforced (SFR) specimen was gradual as compared to abrupt and brittle failure pattern of the non-SFR specimen. They concluded that steel fibers were capable of retarding the propagation of cracks in cement stabilized lateritic soil.

Although, the elastic properties of pavement materials can be determined through laboratory testing programs, the purpose of the present study was to develop a model that can use the properties of the pavement material determined from the laboratory to predict elastic tensile modulus.

\section{METHODOLOGY}

\subsection{Material Properties}

The indirect tensile test was used for the determination of the following properties of the steel fiber reinforced soilcement:

- Tensile strength

- Modulus of Elasticity $\left(\mathrm{E}_{\mathrm{t}}\right)$ in tension

- Modulus of Elasticity $\left(\mathrm{E}_{\mathrm{c}}\right)$

- Horizontal Tensile Strain $\left(\varepsilon_{t}\right)$

- Vertical Compressive Strain $\left(\varepsilon_{c}\right)$

\subsection{Soil Sampling and Classification}

The soil sample was collected from borrow pit along Umuechem Road in Etche Local Government Area of Rivers State, Nigeria. The soil classification and physical property tests were carried out in accordance with BS1377:1975 and AASHTO: 1975. The soil classification test revealed the following properties:

- $\quad$ Natural Moisture Content $=11.31 \%$

- $\quad$ Liquid Limit $=32 \%$

- $\quad$ Plasticity Index $=15.51 \%$

- Proctor Maximum Dry Density $=1960 \mathrm{~kg} / \mathrm{m}^{3}$

- $\quad$ AASHTO Classification = A-2-6 soil

\subsection{Preparation of Soil Specimen}

For the purpose of achieving the objection of the study, specimen preparation was done in accordance with BS1924: 1975 BY USING 7\% cement content (PCA, 1956) and water corresponding to the optimum moisture content. Furthermore, DUBIC steel fibers (animal wires) of $0.5 \mathrm{~mm}$ diameter and $40 \mathrm{~mm}$ long with aspect ratio of 80 were added to the moist soil - cement paste to produce steel fiber reinforced (SFR) cement stabilized lateritic pavement material. The composite was then thoroughly mixed in a mixing tray and compacted in a proctor mould using $2.5 \mathrm{~kg}$ hammer to produce cylindrical specimens $100 \mathrm{~mm} \times 120 \mathrm{~mm}$ dimension. Steel fiber was added in varying amounts of 0 , $1.2,1.4,1.6,1.8$ and $2 \%$ respectively. For each fiber content three specimens were prepared in order to have a weighted average. The indirect tensile strength was then carried out in accordance with Kennedy (1977) and Adedimila (1980). Specimens were then cured at 28 days in moist saw-dust in air-tight plastic containers. The CBR machine was used to apply load through special testing bearings strips $12.7 \mathrm{~mm}$ wide and $110 \mathrm{~mm}$ long which was fabricated from a $100 \mathrm{~mm}$ diameter pipe to enable the seating of the penetration piston on the test specimen (ASTM, 1974). Tensile properties of 
the specimens were determined. Also horizontal tensile strains and vertical compressive strains were measured directly using the DEMEC strain gauge No. 3463 with sensitivity of $1.97 \times 10^{-5}$.

\section{RESULTS}

The results from the indirect tensile testing of specimens are as presented in Table 1 below;

Table 1: SFR Cement Stabilized Lateritic Soil properties from Indirect Tensile Test

\begin{tabular}{|l|l|l|l|l|l|l|l|}
\hline \multicolumn{2}{|l}{ Parameters } & Fiber Content $(\%)$ & \multicolumn{5}{l|}{} \\
\cline { 3 - 9 } & 0 & 1.2 & 1.4 & 1.6 & 1.8 & 2.0 \\
\hline 1 & Tensile Strength, $\mathrm{S}_{\mathrm{T}}\left(\mathrm{N} / \mathrm{mm}^{2}\right)=2 \mathrm{p} / \mathrm{std}$ & 0.62 & 0.65 & 0.68 & 0.7 & 0.55 & 0.4 \\
\hline 2 & Poisson's ratio, $\mu$ & 0.21 & 0.24 & 0.26 & 0.3 & 0.27 & 0.25 \\
\hline 3 & Modulus of Elasticity in Tension, $\mathrm{E}_{\mathrm{T}}\left(\mathrm{N} / \mathrm{mm}^{2}\right)$ & & & & & & \\
& & 36,400 & 38,400 & 42,000 & 46,100 & 30,300 & 21,500 \\
\hline 4 & Modulus of Elasticity in Compression, $\mathrm{E}_{\mathrm{c}}\left(\mathrm{N} / \mathrm{mm}^{2}\right)$ & & & & & & \\
& & 4,580 & 5,720 & 6,890 & 8,540 & 4,350 & 4,170 \\
\hline 5 & Horizontal Tensile Strain, $\mathrm{E}_{\mathrm{t}}\left(\mathrm{x} 10^{-5}\right)$ & & & & & & \\
& & 2.31 & 2.62 & 2.7 & 3.16 & 2.73 & 2.31 \\
\hline 6 & Vertical Compressive Strain, $\mathcal{E}_{\mathrm{c}}\left(\mathrm{x} 10^{-5}\right)$ & 16.89 & 17.16 & 18.56 & 19.41 & 16.08 & 14.04 \\
\hline
\end{tabular}

\section{MODEL DEVELOPMENT}

The following steps were undertaken during the process of developing a prediction model for Tensile Elastic Modulus for the SFR Cement Stabilized Lateritic Soil:

1. Model proposal: the following model was proposed for the prediction of tensile elastic modulus for SFR Cement Stabilized Lateritic Soil:

$$
E_{T}=a\left(\frac{s_{T} * \mu}{\varepsilon_{t}}\right)^{b}-c
$$

Where: $\mathrm{E}_{\mathrm{T}}=$ Tensile Elastic Modulus

$\mathrm{S}_{\mathrm{T}}=$ Tensile strength of specimen

$\mu=$ Poisson's ratio

$\varepsilon_{\mathrm{t}}=$ Horizontal tensile strain

$\mathrm{a}, \mathrm{b}$ and $\mathrm{c}$ are coefficients to be statistically determined

2. Measure tensile strain for each specimen at failure

3. Measure Poisson's ratio for each specimen at failure

4. Determine tensile strength of each specimen at failure

5. Calculate tensile elastic modulus for each specimen at failure

6. Write a non-linear regression equation that satisfies the condition of the general form of the proposed model

7. Input stringed variables into the SPSS software for non linear analysis

\subsection{Developing Proposed Model Using Non Linear Regression Approach in SPSS}

A non linear model is one in which at least one of the parameters appear nonlinearly. More formally, in a nonlinear model, at least one derivative with respect to a parameter should involve that parameter. To solve the non linear regression using SPSS the variables (dependent and independent) were first of all collated into different cells in the "Data View" dialogue box. Next, these variables were stringed and coded into another dialogue box called the "Variable View Cell". Finally model syntax was developed that satisfies the condition of the general form of the model proposed (Draper and Smith, 1998).

\subsection{Non Linear Model Syntax}

The non linear model syntax is of the form as shown below;

$$
E_{T}=a *\left[\frac{\left(S_{T} * \mu\right) * * b}{\left(\varepsilon_{t}^{* * b}\right)}\right]-c
$$

Equation 3 is the non linear syntax model that corroborates the general form of the proposed model in Equation 2 used for analysis in the SPSS program. Furthermore, in SPSS the command $(* *)$ means raising a variable to the power of the coefficient in the same bracket while the command (*) means multiplication. By applying Equation 3 in the SPSS program using results from Table 1 the experimental coefficients were determined as follows, $a=1.30 ; b=1.216$; $\mathrm{c}=12,620$ [See Appendix A: Table $1 \mathrm{a}-\mathrm{c}$ ].

By applying the coefficients obtained the resulting prediction model equation in syntax form becomes;

$$
E_{T}=1.3 *\left[\frac{\left(s_{T} * \mu\right) * * 1.216}{\left(\varepsilon_{t}^{* * 1.216}\right)}\right]-12,620
$$

The actual prediction model can thus be written as;

$$
E_{T}=1.3\left(\frac{s_{T} * \mu}{\varepsilon_{t}}\right)^{1.216}-12,620
$$

\subsection{Validation of Model}


In order to validate the fairness of the derived model, values from indirect tensile test results in Table 1 above were inputted into Equation 5 to determine predicted values of tensile elastic modulus. The values obtained from the predicted model for tensile elastic modulus were then compared with that calculated from laboratory experimentation as in Table 2 and Figure 1. The results of their correlation revealed that the predictive model developed closely simulated calculated values of tensile elastic modulus having an $\mathrm{R}^{2}$ value of 0.964 .

Table 2: Comparison of Calculated and Predicted Tensile

\begin{tabular}{|l|l|l|l|}
\hline \multicolumn{5}{|c|}{ Elastic Modulus, $E_{\mathrm{T}}$} \\
\hline & $\begin{array}{l}\text { Fibre } \\
\text { Content } \\
(\%)\end{array}$ & $\begin{array}{l}\text { Calculated Tensile } \\
\text { Elastic Modulus }\end{array}$ & $\begin{array}{l}\text { Predicted } \\
\text { Elastic } \\
\text { Modulus }\end{array}$ \\
\hline 1 & 0 & 36,400 & $34,712.36$ \\
\hline 2 & 1.2 & 38,400 & $37,977.43$ \\
\hline 3 & 1.4 & 42,000 & $44,179.36$ \\
\hline 4 & 1.6 & 46,100 & $45,208.58$ \\
\hline 5 & 1.8 & 30,300 & $32,710.34$ \\
\hline 6 & 2.0 & 21,500 & $21,719.28$ \\
\hline
\end{tabular}

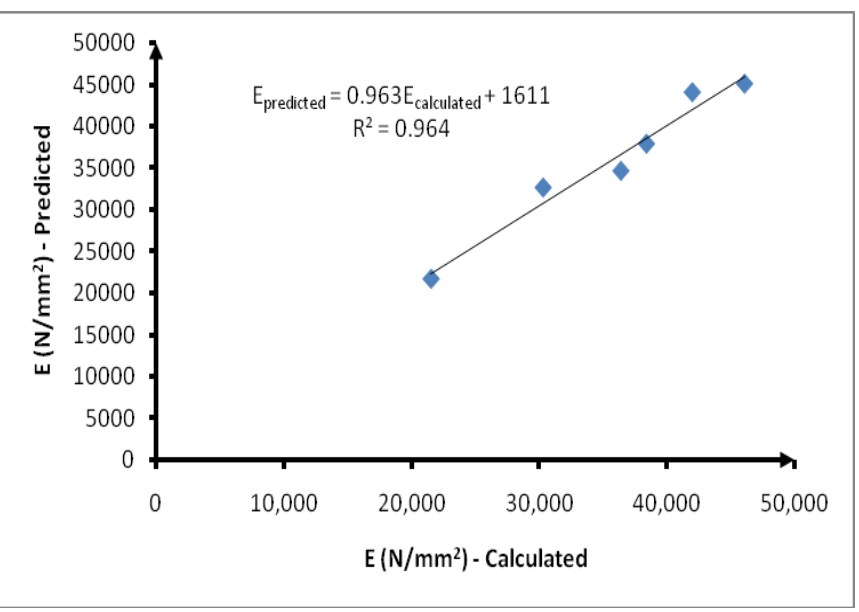

Fig 1: Calibration of Predicted and Calculated Tensile Elastic Modulus

\section{DISCUSSION}

From figure 1, it was observed that the results from the prediction model closely replicated that calculated from laboratory experimentation. Also the similarity of their correlation is such that they are linearly related with the expression as in Equation 6 below with an $\mathrm{R}^{2}$ value of $96.4 \%$.

$$
E_{T(\text { predicted })}=0.963 E_{T(\text { calculated })}+1611
$$

\section{CONCLUSION}

From the foregoing based on the laboratory experiments carried out, results obtained and analysis as presented in the sections above the following conclusions can be made;

1. Since the Derived Prediction Model for Tensile Elastic Modulus from Equation (5) closely simulates results calculated from laboratory experimentation; it can thus be accepted as a means for predicting Tensile Elastic Modulus under similar conditions.

2. The general form of the Derived Prediction Model can be written in simple terms as in Equation 2 above.

3 . The relationship between the derived prediction model for tensile elastic modulus and the calculated tensile elastic modulus from laboratory experimentation is generally linear and expressed as in Equation 6.

\section{REFERENCES}

[1] Adedimila, A. S. (1980) "Indirect Tensile Test Equations for tensile and Elastic properties of Materials", Institute of Civil Engineers, Part 2, Vol. 69, pp.175-184.

[2] Adedimila, A. S. and Ashade, M. O. (1993) "An Alternative to the California Bearing Ratio Test for Cohesive Soils", NSE Technical Transactions, Vol. 28, No. 3, pp. 1-6.

[3] Adedimila, A. S. and Emina C., (1985) "Moisture Effect on Nigeria's Asphalt Paving Mixtures", The Nigerian Engineer, Vol. 20, No. 1.

[4] American Association of State Highway and Transportation Officials: Designation M145 (1975) "Classification System for Soils", AASHTO, Transportation Research Board, Washington.

[5] Annual Book of American Society for Testing Materials Part 10 (1974) "Making and Curing of SoilCement Compression and Flexure Test Specimens in the Laboratory", ASTM Designation D16, pp32-63.

[6] British Standard Institute: BS1377 (1975) "Methods of Test for Soils for Civil Engineering Purposes", BSI, London.

[7] British Standard Institute: BS1924 (1975) "Methods of Test for Stabilized Soils", BSI, London.

[8] Ekwulo, E. O. and Igwe, E. A. (2009) "Rational Properties of Steel Fiber-Cement Stabilized Lateritic Pavement Material", International Journal of Civil Engineering, Vol. 1, No. 1, pp.103-108.

[9] Emesiobi, F. C. (2004a) "Evaluation of Indirect tensile Strength Testing Techniques using Cement Stabilized Lateritic Soils", PhD Thesis, Department of Civil Engineering, RSUST, Port Harcourt, Nigeria.

[10] Emesiobi, F. C. (2004b) "Evaluation of Critical Fatigue and Rutting Strains in Flexible Pavements Designed by Various CBR methods", Paper Review by Journal of Applied Science and Technology (JAST), Centre for Scientific and Industrial Research (CSIR), Ghana.

[11] Emesiobi, F. C. and Aitsebaomo, F. O. (2002) "Testing of Cement Stabilized Lateritic Soil using Compressive Strength and various Indirect tensile Strength Testing Methods", Journal of Construction and Materials Technology, Ota, Vol. 2, No.1, pp.9399.

[12] Hancork, P. and Cuthbertson, R. C. (1970) "The Effect of Fiber and Interfacial Bond in Glass FiberEpoxy Resin Composites", Journal of Material Science, Vol. 5, p.762. 
[13] Kennedy, T. W. (1977) "Characterization of Asphalt Pavement Materials using Indirect Tensile Test", Proceedings Association of Asphalt Paving technologists, San Antonio, Texas.

[14] Naaman, A. E. (1999) "High Performance Fiber reinforced Cement Composites", Concrete Structures for the Future, IABSE Symposium, Paris, pp. 371376.

[15] Nakagawa, H., Akihama, S. and Suenaga, T. (1988) "Mechanial Properties of various types of Fiber Reinforced Concretes", Recent developments: International Conference, University of Wales College of Cardiff, Ed by R. N. Swany and B. Barr, Elsevier Applied Science, London, pp. 523-532.

[16] Oguara, T. M. (1985) "Mechanistic Approach to Design of Highway Pavements in Nigeria", ISSMFE, Golden Jubilee Publication on Geotechnical Practice in Nigeria, Lagos, pp. 139-154.

[17] Oguara, T. M. (2005) "Highway Engineering: Pavement design, Construction and Maintenancet", Treasure Communications Resource Limited, Yenegoa, Bayelsa State, Nigeria.

[18] Oguara, T. M. and Emesiobi, F. C. (2001) "Characteristics of Cement Stabilized Lateritic Soils Using Static Load Indirect tensile Test (Splitting Test)", Journal of Engineering, Vol. 11, No. 1, pp. 39-49, India.

[19] Oguara, T. M., Emesiobi, F. C. and Odunwa, P. (2001) "Relationship between Indirect Tensile Strength and Marshall Stability of Asphaltic Concrete", Journal of Engineering, Vol. 11, No. 1, India, pp.51-68.

[20] Pavement Interactive Core Series (2008) "Available at http://www.pavementinteractive.org (Accessed: August 13, 2008).

[21] Portland Cement Association (1956) "Soil Cement Laboratory Handbook", PCA Skotie, Illinois.

[22] Shahid, M. A. and Thom, N. H. (1998) "Steel Fiber Reinforced in Cement Bond Bases", Proceedings of the Institute of Civil Engineers (Transport). 